\title{
Effects of insertion speed and trocar stiffness on the accuracy of needle position for brachytherapy
}

\author{
Carl S. McGill ${ }^{\text {a) }}$ and Jonathon A. Schwartz \\ Biomedical Engineering Department, University of Michigan, Ann Arbor, Michigan 48109
}

Jason Z. Moore

Department of Mechanical and Nuclear Engineering, The Pennsylvania State University, State College, Pennsylvania 16802

Patrick W. McLaughlin

Department of Radiation Oncology, University of Michigan, Ann Arbor, Michigan 48109

\begin{abstract}
Albert J. Shih
Biomedical Engineering Department, University of Michigan, Ann Arbor, Michigan 48109 and Mechanical Engineering Department, University of Michigan, Ann Arbor, Michigan 48109
\end{abstract}

(Received 9 November 2011; revised 8 February 2012; accepted for publication 9 February 2012; published 13 March 2012)

\begin{abstract}
Purpose: In prostate brachytherapy, accurate positioning of the needle tip to place radioactive seeds at its target site is critical for successful radiation treatment. During the procedure, needle deflection leads to seed misplacement and suboptimal radiation dose to cancerous cells. In practice, radiation oncologists commonly use high-speed hand needle insertion to minimize displacement of the prostate as well as the needle deflection. Effects of speed during needle insertion and stiffness of trocar (a solid rod inside the hollow cannula) on needle deflection are studied.

Methods: Needle insertion experiments into phantom were performed using a $2^{2}$ factorial design ( 2 parameters at 2 levels), with each condition having replicates. Analysis of the deflection data included calculating the average, standard deviation, and analysis of variance (ANOVA) to find significant single and two-way interaction factors.

Results: The stiffer tungsten carbide trocar is effective in reducing the average and standard deviation of needle deflection. The fast insertion speed together with the stiffer trocar generated the smallest average and standard deviation for needle deflection for almost all cases.

Conclusions: The combination of stiff tungsten carbide trocar and fast needle insertion speed are important to decreasing needle deflection. The knowledge gained from this study can be used to improve the accuracy of needle insertion during brachytherapy procedures. (C) 2012 American Association of Physicists in Medicine. [http://dx.doi.org/10.1118/1.3689812]
\end{abstract}

Key words: prostate brachytherapy, needle deflection, trocar material

\section{INTRODUCTION}

Accurate placement of needles is important when performing multiple medical diagnostic and therapeutic procedures such as anesthesia, neurosurgery, tissue biopsy, and brachytherapy. ${ }^{1-4}$ Brachytherapy is a radiation treatment option performed once prostate cancer, the most frequently diagnosed cancer in men, ${ }^{5}$ is detected in the early stages. When performing brachytherapy, a needle is used to guide radioactive seeds into the prostate gland in order to eradicate cancerous cells. ${ }^{6,7}$ The brachytherapy needle consists of two main parts, an inner solid rod called the trocar and an outer hollow cylinder called the cannula. The needle, which is the combination of the cannula and trocar, is inserted into the prostate and deflects due to tissue deformation and complex anatomic structures in and around the prostate. ${ }^{8-10}$ Clinical studies have shown that when the needle deflects, the radioactive seed does not attain its target, and consequently, the radiation dose deviates from the targeted level. ${ }^{8}$ Adverse side effects such as rectal bleeding, urinary and bowel incontinence, erectile dysfunction, and tissue damage occur when the radioactive seeds are misplaced. ${ }^{8-10}$
To improve needle insertion accuracy and radioactive seed placement during brachytherapy, studies have been conducted on the needle and needle insertion procedure by exploring different designs of needle tips, ${ }^{11,12}$ performing different insertion methods, ${ }^{12-16}$ and modeling needle-tissue interaction. ${ }^{17-19}$ Abolhassani et $a .^{20}$ have done an in-depth survey that includes modeling needle insertion forces and tissue deformation, along with the effect different needle trajectories and paths have on tissue deformation. Additionally, McGill et al. ${ }^{21}$ designed a grid (an array of holes through a block that supports the needle prior to entering the tissue) that reduces the clearance between the grid hole inner diameter and the needle outer diameter. Clinically, the 18-gauge needle is the standard for brachytherapy. A smaller diameter, 20-gauge, needle has recently been tested to reduce the invasiveness. Stiffness of the thin 20-gauge needle is only about $26 \%$ of the current 18 -gauge needle based on the beam deflection theory. A literature review shows that no study has been performed on using a higher Young's modulus material for the trocar to increase the stiffness and reduce the deflection of the needle combination during insertion. One 
of the goals of this paper is to investigate the effect of trocar stiffness on the needle deflection.

Insertion techniques used to move the needle through the body are important to reach the desired target within the prostate gland. Currently, manual needle insertions utilizing a quick flick of the wrist to produce high-speed is performed by physicians to achieve the quick and easy penetration of stiffer tissue, such as the perineum skin, during the brachytherapy procedure. Even though the high needle insertion speed does not stay constant during the entire needle path, this instantaneous high-speed has been measured to be around $650 \pm 200 \mathrm{~mm} / \mathrm{s}^{21}{ }^{21}$ however, in actual brachytherapy procedures, the needle path is non-uniform at the hands of skilled physicians. Mahvash and Dupont ${ }^{22}$ concluded from experimenting on pig hearts and modeling it as a viscoelastic material that increasing needle insertion velocity decreases needle deflection and tissue damage. Researchers have studied speed effects on needle insertion, ${ }^{12-15,23}$ but the speed range is around $10 \mathrm{~mm} / \mathrm{s}$, with a maximum of $200 \mathrm{~mm} / \mathrm{s}$ when using a robotic-assisted tool. ${ }^{23}$ A pneumatic actuator has been applied to generate a faster needle insertion speed (over $2300 \mathrm{~mm} / \mathrm{s}$ ). The pneumatic actuator was chosen over linear motor because of its high-speed capability, cleanliness, and cost-effectiveness for clinical applications. A cadaver prostate brachytherapy test using the pneumatic actuator generating such high speeds has been conducted and demonstrated the feasibility of such high-speed in the clinical setting. Another goal of this paper is to study the effect of such fast insertion speed on needle deflection.

This paper begins with the overview of experimental setup, followed by an introduction to the pneumatic device and trocar material. Next, an explanation of the experimental design and analysis method are presented. Subsequently, results on the average and standard deviation of needle deflection are provided. Significant factors identified with the deflection data, discussion of the findings, and the conclusion of this study are then given.

\section{MATERIALS AND METHOD}

\section{II.A. Overview of experimental setup}

The setup (Fig. 1) for the experiment includes a grid, phantom, phantom holder, measurement datum stand, digital depth gauge, pneumatic device (comprise of the pneumatic actuator, linear guide, linear encoder, and needle plate), and needle. The needle grid, made of AISI 316 stainless steel (SS), has a $13 \times 13$ array of $1.303 \mathrm{~mm}$ diameter holes and thickness of $50.8 \mathrm{~mm}$. This grid, which was tested as the tight thick grid in Ref. 21, has a $33 \mu$ m diametric clearance between the grid hole inside diameter and needle outside diameter and is $30.5 \mathrm{~mm}$ longer than the current commercial 18 -gauge grids, which has $76 \mu \mathrm{m}$ diametric clearance and $20.3 \mathrm{~mm}$ length.

The phantom, made of polyvinylchloride (PVC) modified with plastisol, was created from a 1:1 ratio of regular liquid plastic to plastic softener (M-F Manufacturing, TX). An indentation test ${ }^{24}$ performed on this PVC phantom of the same ratio produced a Young's modulus of $12 \mathrm{kPa}$, a value similar to porcine liver; ${ }^{25}$ thus, the mechanical properties of PVC phantom mimic that of tissue. The phantom block had dimensions of $85 \mathrm{~mm}$ length, $75 \mathrm{~mm}$ width, and $50 \mathrm{~mm}$ height. The $85 \mathrm{~mm}$ phantom length was the distance the needle traveled during experimentation. The phantom width-height ratio provided enough support upon the phantom holder and adequate area for needle insertion to occur when using several height levels within the grid.

The phantom holder, made from $12.7 \mathrm{~mm}$ thick polycarbonate, was constructed to have $90 \mathrm{~mm}$ length, $100 \mathrm{~mm}$ width, and $75 \mathrm{~mm}$ height and held the phantom as in Ref. 21. The phantom holder provided a consistent location to obtain needle position. The phantom holder and phantom were placed $25 \mathrm{~mm}$ from the front of the needle grid. This distance mimics the gap found between the patient's skin and grid during brachytherapy procedures.

The measurement datum stand and digital depth gauge (Mitutoyo Model VDS-6 DCX) are the components that comprised the needle deflection measurement apparatus discussed in Ref. 21. Using the datum stand, the depth gauge mechanically measures position coordinates at the phantom entrance and exit in the $x$ - and $y$-directions, perpendicular to the needle axial direction. Using the position coordinates, the $X_{\text {deflection }}$ and $Y_{\text {deflection }}$, the needle deflection in the horizontal and vertical direction, respectively, were calculated. Additionally, the resultant/radial deflection $R\left(=\sqrt{X_{\text {deflection }}^{2}+Y_{\text {deflection }}^{2}}\right)$ data were calculated through the $85 \mathrm{~mm}$ phantom length. ${ }^{21}$

The descriptions on the pneumatic device and the needles with the stiffer trocar used in this experiment are explained in Secs. II A 1 and II A 2, respectively.

\section{II.A.1. Pneumatic device}

This device, shown in Fig. 1, uses a pneumatic actuator with a $19 \mathrm{~mm}$ bore $150 \mathrm{~mm}$ stroke (Numatics Model SG543136-1) to move the linear guide and push the attached needle plate. Within the pneumatic actuator casing are linear bearings that enable the linear guide to move forward and backward in the $z$-direction. Rubber stoppers, placed at the end of the linear guide, were used to control the stoke length, and thus guarantee a constant needle depth for each insertion trial. The needle plate, having the same $13 \times 13$ array of holes as the grid, pushed the needle through the grid and into the phantom. The holes within the needle plate provide a means to enclose the back of the needle and thus push the needle through the grid, when the actuator is activated. The speed of the pneumatic actuator was controlled by varying the inlet air pressure to the actuator.

\section{II.A.2. Needle stiffness}

Mick Radio-Nuclear Instruments, Inc. (NY, USA) produces 18-gauge prostate brachytherapy needles (Model MTP-1820-C) that were used in this experiment. The needle consists of two main parts made of AISI 304 stainless steel: the inner solid trocar rod and the outer hollow cannula. The trocar has a diamond point (three-plane) tip while the cannula tip is square cut. The needle combination (trocar and 


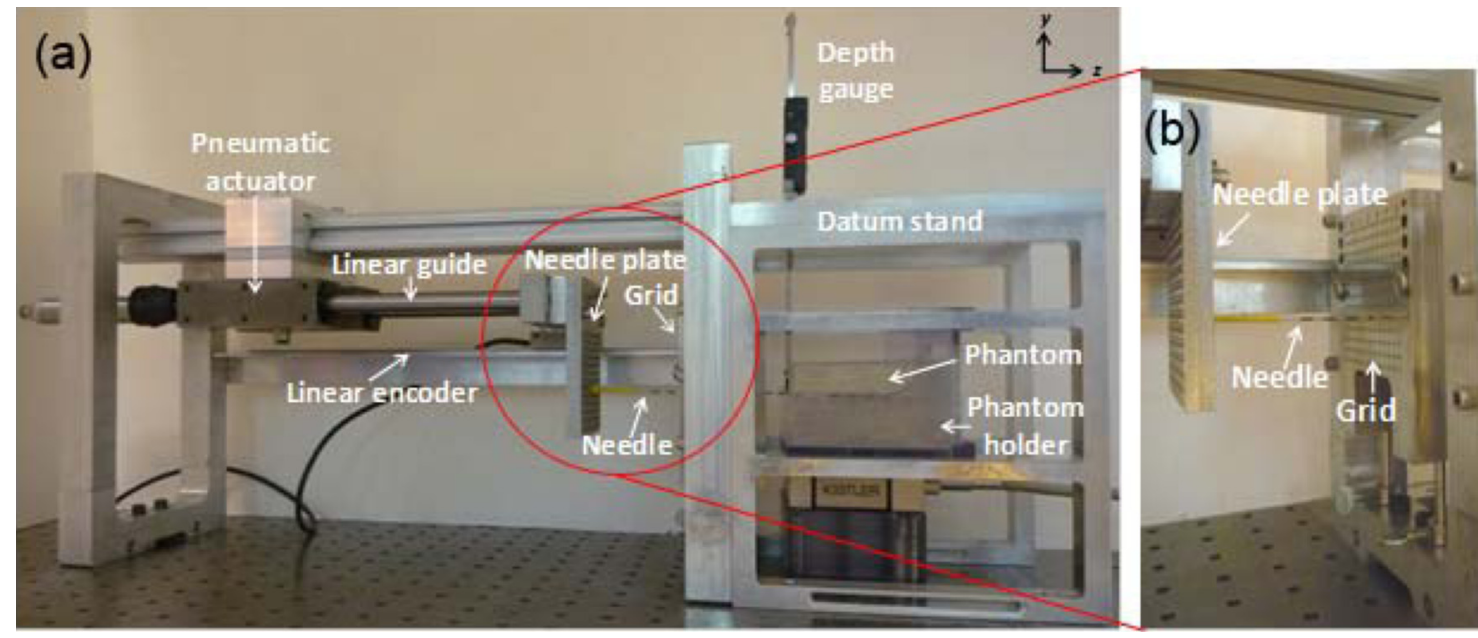

FIG. 1. (a) Experimental setup, which includes the grid, phantom, phantom holder, measurement datum stand, digital depth gauge, pneumatic device (pneumatic actuator, linear guide, linear encoder, and needle plate), and needle and (b) close-up view of the needle plate, needle, and grid.

cannula) must resist various deflecting forces exerted on the needle during insertion into tissues. A mechanical property that indicates stiffness of a material is called Young's modulus or modulus of elasticity. The Young's modulus of the current trocar made of AISI 304 SS is about $200 \mathrm{GPa}^{26}$ To increase the stiffness of the needle combination, the tungsten carbide with $6 \%$ cobalt, denoted as WC, with a Young's modulus of around $630 \mathrm{GPa},{ }^{27}$ was used as the material for the solid trocar. This WC trocar has the same tip angle $\left(10.5^{\circ}\right.$ angle), diameter $(1.01 \mathrm{~mm})$, and length $(20.5 \mathrm{~cm})$ as the current Mick AISI 304 stainless steel trocar (Fig. 2) and can be inserted into the current hollow AISI 304 stainless steel cannula.

\section{II.A.3. Needle insertion setup and speed}

During the experiment, the needle was set to the insertion position by placing the needle tip within a hole in the grid (trocar orientation was random relative to the bevel cuts at the trocar's tip), while the other end was placed within the matching hole in the needle plate. The matching hole within the needle plate enabled the needle to be parallel with the optical table, which is the base of the experimental setup. After placing the needle tip within the grid (the same starting position for all insertions for a given grid coordinate), the air valve was set to the desired air pressure. The device was secured to the optical table to prevent movement during insertion. The linear optical encoder (Fig. 1) measured the position of the needle plate during insertion. A data acquisition system (National Instruments Model NI DAQPad-6015) and LabVIEW, sampling rate of $50 \mathrm{kHz}$, were used to record the data. Using the displacement and time data, the insertion speed produced by the pneumatic device was calculated. Air flow at $140 \mathrm{kPa}$ produced speed of $1120 \pm 40 \mathrm{~mm} / \mathrm{s}$, while air flow at $410 \mathrm{kPa}$ produced speed at $2370 \pm 30 \mathrm{~mm} / \mathrm{s}$. These two speeds represent the low limit and close to the highest speed of the pneumatic actuator. After the needle was inserted into the phantom, position coordinates were obtained at the entrance and exit of the phantom to calculate needle deflection $\left(X_{\text {deflection }}\right.$ and $\left.Y_{\text {deflection }}\right)$. Measurements were repeated for each insertion. The needle tip cutting edges were examined after each test, and no visible wear was observed for both stainless steel and tungsten carbide trocar.

\section{II.B. Design of experiments}

\section{II.B.1. Factors and conditions}

A $2^{k}$ factorial design experiment, ${ }^{28}$ where $k=2$ (factors), was executed in this study. The two factors were needle insertion speed and material used for the trocar, as shown in Table I. Using the $2^{2}$ factorial design experiment, four condition combinations were produced. Each combination had ten replicates producing a total of 40 data points for the entire experiment. The sample size $(n=10)$ was calculated using an operating characteristic (OC) curve and appropriate sample size equation, which was presented in Ref. 21. In Table I, the first column shows the four conditions studied in this experiment while the next two columns state the factor level for the needle speed and material used for the trocar (SS and WC) at the respective condition. The last two columns identify the main effect (the overall effect of one factor) and two-way interaction (the effect of one factor depending on the level of the second factor), which are represented by the test no. and condition.

\section{II.B.2. Grid coordinates, alignment, and randomization}

A $5 \times 8$ section (row by column) in the lower region of the grid was used to perform all 40 needle insertion trials. Ten coordinates, which represented the ten replicates, were $1.01 \mathrm{~mm}$

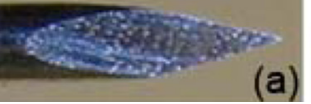

(a)



FIG. 2. Trocars made of (a) AISI 304 stainless steel and (b) tungsten carbide in $6 \%$ cobalt. 
TABLE I. Design matrix of condition combinations.

\begin{tabular}{|c|c|c|c|c|}
\hline \multirow[b]{2}{*}{$\begin{array}{l}\text { Test No.: } \\
\text { conditions studied }\end{array}$} & \multicolumn{2}{|c|}{ Factors } & \multirow[b]{2}{*}{$\begin{array}{l}\text { Main } \\
\text { effect }\end{array}$} & \multirow[b]{2}{*}{$\begin{array}{l}\text { Two-way } \\
\text { interaction }\end{array}$} \\
\hline & $\begin{array}{l}\text { Needle speed } \\
(\mathrm{mm} / \mathrm{s})\end{array}$ & $\begin{array}{l}\text { Trocar } \\
\text { material }\end{array}$ & & \\
\hline 1: Control & 1120 & SS & & \\
\hline 2: Speed & 2370 & SS & $\mathrm{X}$ & \\
\hline 3: Material & 1120 & WC & $\mathrm{X}$ & \\
\hline 4: Speed/material & 2370 & WC & & $X$ \\
\hline
\end{tabular}

assigned to one condition combination. Using the "Latin rectangle" design for grid coordinates for each condition and replicate, discussed in Ref. 21, all condition combinations were performed at each row number and column letter, for each needle insertion.

Before beginning the experiment, the grid was aligned to the two datum surfaces on the datum stand via inserting by hand and measuring a reference needle, which was placed through a hole that does not insert into the phantom. Adjustment was made to the orientation of the grid to produce a zero deflection on the needle. Additionally, a full randomization occurred throughout the entire experiment via: (1) assignment of the ten grid coordinates (as shown in Ref. 21) to a condition combination that was used for the ten replicates; (2) order of grid coordinates/replicates; and (3) assignment of factors to two coding letters, used for analysis purposes.

\section{II.C. Analysis methods}

Each data set $\left(X_{\text {deflection }}, Y_{\text {deflection, }}\right.$ and $R$ ) were analyzed separately; analysis included computation of averages,

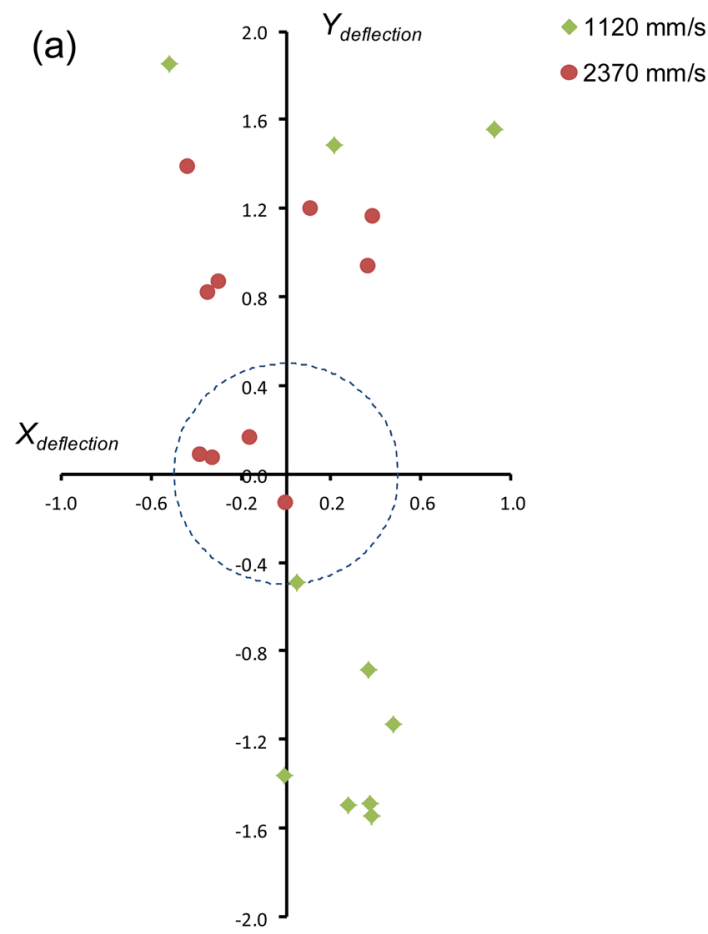

standard deviations, and $p$-values. Averages provided a method to compare accuracy of needle insertions while standard deviations compare precision and closeness of replicates with each other within each condition. Using the needle deflection effects to analyze the data, $p$-values were used to show which factor(s) had a significant ( $p$-value $<0.05)$ effect on needle deflection. A $2^{2}$ factorial design analysis of variance (ANOVA) was performed on the $X_{\text {deflection, }} Y_{\text {deflec- }}$ tion, and $R$ data, using the statistical software Minitab (State College, PA). All 40 data points from the experiment were used as the response variables for the $X_{\text {deflection, }}, Y_{\text {deflection }}$ and $R$ data, while the needle speed and trocar material were entered as the two-level factors within MINITAB. Coded units, -1 for low settings (e.g., both factor levels for test \#1) and +1 for high settings (e.g., both factor levels for test \#4), were used to define the factor levels. Coded units enable the experimental design to be orthogonal, thus MINITAB is able to estimate model terms independently.

\section{RESULTS AND DISCUSSIONS}

\section{III.A. Average and standard deviation of needle deflection}

All $40 X_{\text {deflection }}$ and $Y_{\text {deflection data points are plotted in }}$ Fig. 3. Using Grubbs' test, ${ }^{29,30}$ data points within each condition did not deviate from the other points/replicates, thus outliers were not detected within any condition. All 40 data points for $X_{\text {deflection }}, Y_{\text {deflection }}$, and $R$ were analyzed to obtain the average and standard deviation of the needle deflection; results are summarized in Table II and Fig. 4. The average represents accuracy of needle insertion while the standard

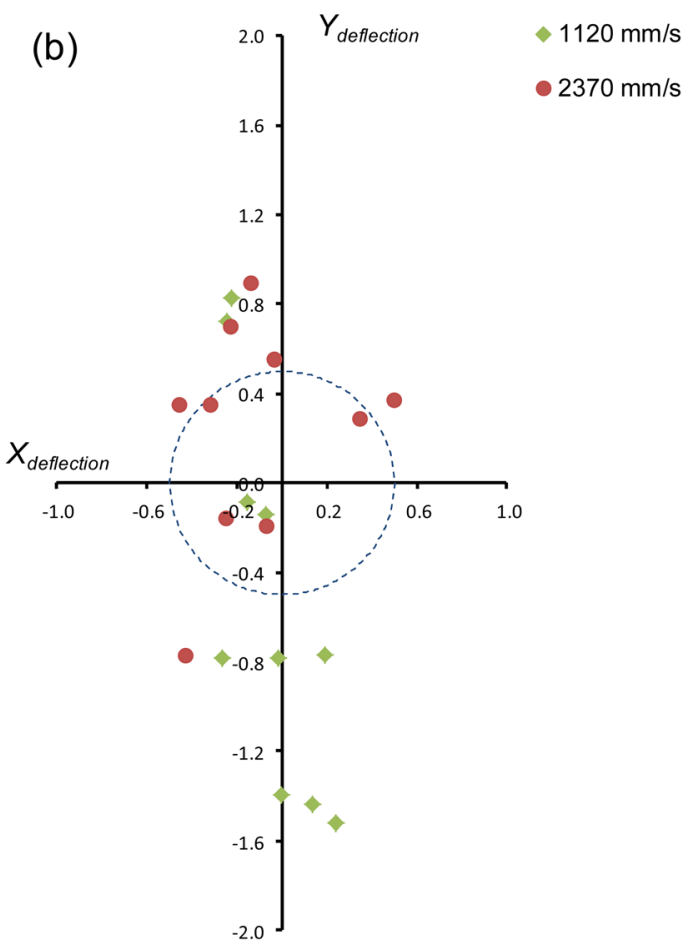

FIG. 3. $X_{\text {deflection }}$ and $Y_{\text {deflection }}$ data points (in $\mathrm{mm}$ ) at speeds of $1120 \mathrm{~mm} / \mathrm{s}$ and $2370 \mathrm{~mm} / \mathrm{s}$ using a trocar made of (a) SS and (b) WC. A $0.5 \mathrm{~mm}$ circle is drawn in order to have a means of visualizing how many and how far data points were from the target $(0,0)$. 
TABLE II. Average and standard deviation of needle deflection.

\begin{tabular}{|c|c|c|c|c|c|c|c|}
\hline \multirow[b]{2}{*}{ Needle speed (mm/s) } & \multirow[b]{2}{*}{ Trocar material } & \multicolumn{3}{|c|}{ Average } & \multicolumn{3}{|c|}{ Standard deviation } \\
\hline & & $X_{\text {deflection }}(\mathrm{mm})$ & $Y_{\text {deflection }}(\mathrm{mm})$ & $R(\mathrm{~mm})$ & $X_{\text {deflection }}(\mathrm{mm})$ & $Y_{\text {deflection }}(\mathrm{mm})$ & $R(\mathrm{~mm})$ \\
\hline \multirow[t]{2}{*}{1120} & SS & 0.25 & -0.35 & 1.39 & 0.37 & 1.41 & 0.42 \\
\hline & WC & -0.04 & -0.54 & 0.87 & 0.18 & 0.85 & 0.48 \\
\hline \multirow[t]{2}{*}{2370} & SS & -0.11 & 0.66 & 0.78 & 0.31 & 0.55 & 0.47 \\
\hline & WC & -0.10 & 0.24 & 0.57 & 0.31 & 0.49 & 0.23 \\
\hline
\end{tabular}

deviation represents the precision and closeness of replicates to each other.

Taking the average of all the $X_{\text {deflection }}$ data revealed a $0.60 \mathrm{~mm}$ shift to the right, while the $Y_{\text {deflection }}$ data produced a slight shift of $0.01 \mathrm{~mm}$ in the up direction. The shift in the data is possible because the needle and needle grid, which were calibrated via a slow hand needle insertion, did not have the same calibration as a needle inserted with the faster speed produced by the pneumatic device. To resolve the difference in calibration, a readjustment occurred by shifting the $X_{\text {deflection }}$ data $0.60 \mathrm{~mm}$ to the left. Since the $Y_{\text {deflection }}$ data shift was small, those data points were not altered. The $X_{\text {deflection }}$ data were investigated and verified that a common effect occurred within all factor combination. The original and shifted data results including standard deviation, average (minus the shift), and statistics were the same for both data set. Furthermore, adjustment of the $X_{\text {deflection }}$ data occurred by shifting the data to obtain a new average $X_{\text {deflection data }}$ close to 0 , which is a similar value as the raw $Y_{\text {deflection }}$ data.

Initial observation of Fig. 3 displays needle deflection mainly in the $Y_{\text {deflection }}$ data, when compared to the $X_{\text {deflection }}$ data. Bias is present within the $Y_{\text {deflection }}$ data for all parameters studied because of the boundary conditions of the phantom. The top of the phantom is exposed while the entire bottom and 50\% of both sides ( $x$-directional deflection) of the phantom are constrained via the phantom holder (Fig. 1). Additionally, there is a bias in the positive $y$-direction [Fig. 3(a)] for the $2370 \mathrm{~mm} / \mathrm{s}$ (higher speed) because higher speeds produce higher forces. Higher force produces higher needle deflection when the less stiff trocar (stainless steel) is used compared to the stiffer tungsten carbide trocar [Fig. 3(b)].

In Table II, the average of the needle deflection provides accuracy of the insertion while standard deviation provides precision and closeness of the replicates to each other. The

(a)

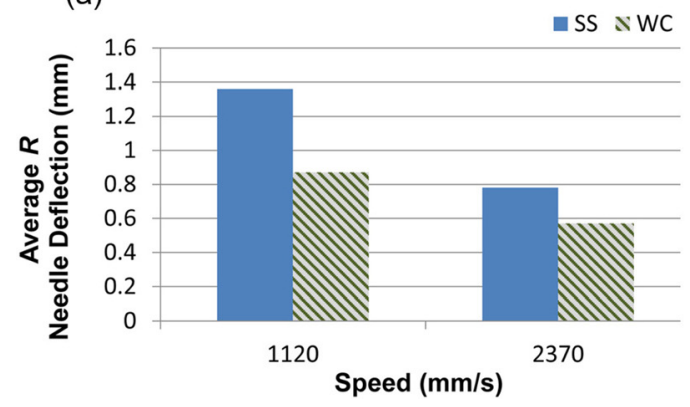

effects of trocar material and needle insertion speed are discussed:

(i) Trocar material: In five out of the six cases for $X_{\text {deflection, }}$

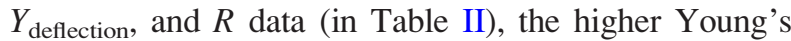
modulus WC trocar material decreases the average of the needle deflection, for a given insertion speed. The only exception was the $Y_{\text {deflection data }}$ at $1120 \mathrm{~mm} / \mathrm{s}$ insertion speed. For standard deviation, four out of the six cases showed a decrease in standard deviation, with an additional one case staying the same, when the WC material was used during needle insertion. The only exception ( $R$ data at $1120 \mathrm{~mm} / \mathrm{s}$ insertion speed) observed to having a slightly higher standard deviation value, an increase of $0.06 \mathrm{~mm}$, when using the $\mathrm{WC}$ trocar during needle insertion. One explanation for this finding is that the stiffness of the trocar plays a more dominate role at faster needle insertion speeds, as shown with six out of the six cases decreasing (with one case staying the same) the average and standard deviation of the needle deflection when the WC and faster needle insertion speed $(2370 \mathrm{~mm} / \mathrm{s})$ were used.

(ii) Needle speed: Inserting the needle at the faster speed $(2370 \mathrm{~mm} / \mathrm{s})$ reduces the average needle deflection for four out of the six cases for the $X_{\text {deflection }}, Y_{\text {deflection }}$, and $R$ data, for a given trocar material. The two exceptions were the WC for the $X_{\text {deflection }}$ data, which produced a small increase of $0.06 \mathrm{~mm}$, and SS for the $Y_{\text {deflection }}$ data; both have a higher value when inserting the needle at the faster speed. For standard deviation of needle deflection, both cases of the $Y_{\text {deffection }}$ data values and one of each of the $X_{\text {deflection }}$ and $R$ data are reduced (total of four out of six cases), when a speed of $2370 \mathrm{~mm} / \mathrm{s}$ was used. The

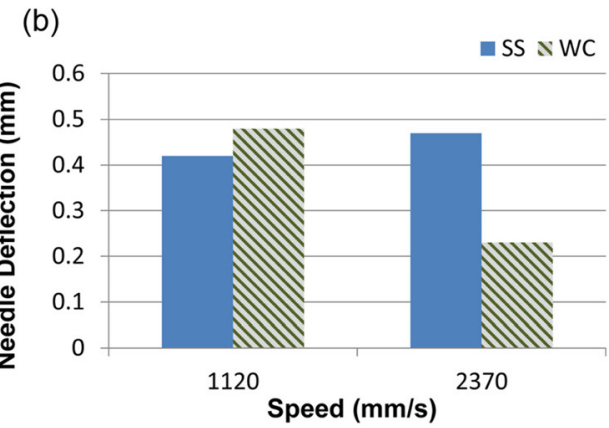

FIG. 4. $R$ data: (a) average and (b) standard deviation of needle deflection of SS and WC trocar material inserted at $1120 \mathrm{~mm} / \mathrm{s}$ and $2370 \mathrm{~mm} / \mathrm{s}$. 
two exceptions, SS for the $R$ data, which increased by a value of $0.05 \mathrm{~mm}$ and WC for the $X_{\text {deflection }}$ data, did not decrease the standard deviation value when inserted at the faster speed. One explanation is that the faster speed of $2370 \mathrm{~mm} / \mathrm{s}$ usually overcomes the tissue deformation better during insertion than the slower speed, thus the faster inserted needle is able to produce consistent accurate and precise needle insertion.

Figure 4 summarizes the $R$ needle deflection findings shown in Table II, illustrating the WC material inserted at the faster speed of $2370 \mathrm{~mm} / \mathrm{s}$ produced the least amount of average $R$ deflection and the least amount of standard deviation in $R$. The WC trocar material inserted at the faster speed (2370 $\mathrm{mm} / \mathrm{s})$ also improved the $X_{\text {deflection }}$ and $Y_{\text {deflection }}$ averages and standard deviations for almost all (10 out of 12) cases in Table II, which includes one case staying the same, for the $X_{\text {deflection }}, Y_{\text {deflection, }}$ and $R$ results when compared to the WC trocar inserted at the slower speed $(1120 \mathrm{~mm} / \mathrm{s})$ and SS trocar inserted at the faster speed $(2370 \mathrm{~mm} / \mathrm{s})$.

The positive attributes of WC and faster speed are also illustrated by visual comparison in Fig. 3(b), which shows more replicates of the WC inserted at a speed of $2370 \mathrm{~mm} / \mathrm{s}$ are within or closer to the $0.5 \mathrm{~mm}$ radius circle. This supports the conclusion that WC and the faster insertion speed $(2370 \mathrm{~mm} / \mathrm{s})$ improve needle position accuracy and consistency.

\section{III.B. Deflection significant factors}

Table III provides the $p$-value for the main effects and two-way interactions of $X_{\text {deflection, }}, Y_{\text {deflection, and } R \text { data, with }}$ significant values $(p$-value $<0.05)$ marked in bold. Significant main effects included the needle speed for $X_{\text {deflection, needle }}$ speed for $Y_{\text {deflection, and needle speed and trocar material for }}$ $R$. One observation to mention in Table III is that the needle speed factor was significant for all data types $\left(X_{\text {deflection }}, Y_{\text {de- }}\right.$ flection, and $R$ ); thus the needle speed, with the contribution of trocar material (being significant with $R$ data), are both important to decreasing the needle deflection.

\section{III.C. Correlation tests}

Before performing the ANOVA tests, $X_{\text {deflection, }} Y_{\text {deflection, }}$ and $R$ residual data (observation data minus mean) were confirmed to be independent (plot of residual versus time order of data collection), normally distributed (normal probability plot of residual), and show homoscedasticity (plot of residuals versus fitted data). ${ }^{28}$ Abnormal trends did not exist within the data plot when MINITAB was used. Additionally, correlation tests

TABLE III. $p$ values $\left(<0.05\right.$ are bolded) for $X_{\text {deflection }}, Y_{\text {deflection, and } R \text { data. }}$

\begin{tabular}{lccc}
\hline \hline & \multicolumn{3}{c}{$p$-value } \\
\cline { 2 - 4 } Factor(s) & $X_{\text {deflection }}$ & $Y_{\text {deflection }}$ & $R$ \\
\hline Needle speed & $\mathbf{0 . 0 3 4}$ & $\mathbf{0 . 0 0 4}$ & $\mathbf{0 . 0 0 1}$ \\
Trocar material & 0.134 & 0.296 & $\mathbf{0 . 0 0 8}$ \\
Speed/material & 0.128 & 0.682 & 0.239 \\
\hline \hline
\end{tabular}

were performed to test deviation magnitudes on the absolute value of the data, using the Pearson Correlation test, and correlation within the direction of the data using the Rayleigh test. $^{31}$ Results from the Pearson correlation was 0.266 ( $p$-value $=0.098)$, while Rayleigh test produced a value of 0.12 , which was smaller than the critical value of 0.27 . Both results were insignificant and less than the critical value, respectively; thus correlation did not occur within the data. Therefore, the magnitude of the absolute $X_{\text {deflection }}$ and $Y_{\text {deflection }}$ data and the $x$ - and $y$ - direction of the data are both independent.

\section{CONCLUSIONS}

This experiment produced results that show the importance of inserting a stiffer trocar at speeds much faster than what can be produced by hand insertion or current robotic devices that are in literature. The WC trocar material inserted at a faster speed $(2370 \mathrm{~mm} / \mathrm{s})$ produced less average needle deflection and lower average standard deviation of needle deflection than the SS trocar material inserted at slower speed $(1120 \mathrm{~mm} / \mathrm{s})$ for each of the $R$ data. The WC trocar inserted at the faster speed $(2370 \mathrm{~mm} / \mathrm{s})$ produced the smallest results for average and standard deviation for each of the $Y_{\text {deflection }}$ and $R$ data. Furthermore, statistical analysis showed significant $p$-values for $X_{\text {deflection, }}, Y_{\text {deflection, }}$, and $R$ data for the speed factor and $R$ data for the material factor.

This research discovers the optimal combination of trocar material and insertion speed. The optimal insertion speed to minimize the needle deflection is not investigated. Such optimal needle speed, which depends on the setup condition and phantom, does exist and is a good topic for future study. A few limitations of this study include using a homogenous phantom instead of the heterogeneous tissue and experimenting with only two pneumatic insertion speeds. The phantom provided a consistent specimen to perform repeated needle insertion in order to confirm decreased needle deflection. The observed effect of decreasing needle deflection with higher insertion speeds produced by the pneumatic device could contribute to improve targeting of the needle when inserting through the prostate tissue. Additionally, another limitation consists of calibrating the needle grid to the pneumatic device. This could be a potential source of bias, even though correlation tests were performed on the data to identify bias within the result. Although this experimental design has few factors for an idealized setup, new concepts and materials are introduced and its findings can be of interest for future investigation. Future work of this research includes studying the optimal needle speed to minimize needle deflection in phantom test and investigating the feasibility of the high-speed needle obtaining more accurate targeted positions in a mobile and deformable phantom, which represents the prostate. Additionally, the pneumatic device and WC trocar will be used to experiment on cadaver and animal models to confirm accurate needle insertion within a prostate.

\section{ACKNOWLDGMENTS}

The authors would like to thank Dr. Edward Rothman from the Statistics Department at the University of Michigan 
for his assistance with the statistical analysis. The authors would also like to acknowledge the support of National Science Foundation Award CMMI Grant No. \#0825795 and the University of Michigan Radiation Oncology Department.

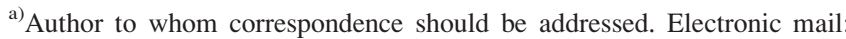
cmcgillz@umich.edu

${ }^{1}$ J. Moore, C. Clarke, D. Bainbridge, C. Wedlake, A. Wiles, D. Pace, and T. Peters, "Image guidance for spinal facet injections using tracked ultrasound," Medical Image Computing and Computer-Assisted InterventionMICCAI, London, England, 2009, pp. 516-523.

${ }^{2}$ H. Xu, A. Lasso, S. Vikal, P. Guion, A. Krieger, A. Kaushal, L. L. Whitcomb, and G. Fichtinger, "MRI-guided robotic prostate biopsy: A clinical accuracy validation," Medical Image Computing and Computer-Assisted Intervention - MICCAI, Beijing, China, 2010, pp. 383-391.

${ }^{3}$ R. R. Shamir, L. Joskowicz, and Y. Shoshan, "Optimal landmarks selection and fiducial marker placement for minimal target registration error in image-guided neurosurgery," Proc. SPIE 7261, 72612N (2009).

${ }^{4}$ S. Song, N. B. Cho, G. Fischer, N. Hata, C. Tempany, G. Fichtinger, and I. Iordachita, "Development of a pneumatic robot for MRI-guided transperineal prostate biopsy and brachytherapy: New approaches," IEEE International Conference on Robotics and Automation, Anchorage, Alaska, 2010, pp. 2580-2585.

${ }^{5}$ American Cancer Society, Cancer Facts and Figures 2011 (American Cancer Society, Atlanta, GA, 2011).

${ }^{6}$ A. T. Porter, J. C. Blasko, P. D. Grimm, S. M. Reddy, and H. Ragde, "Brachytherapy for prostate cancer," CA Cancer J. Clin. 45, 165-178 (1995)

${ }^{7}$ J. C. Blasko, "Brachytherapy," Urology 55, 306-308 (2000).

${ }^{8}$ S. Nath, Z. Chen, N. Yue, S. Trumpore, and R. Peshcel, "Dosimetric effects of needle divergence in prostate seed implant using ${ }^{125} \mathrm{I}$ and ${ }^{103} \mathrm{Pd}$ radioactive seeds," Med. Phys. 27, 1058-1066 (2000).

${ }^{9}$ N. N. Stone and R. G. Stock, "Complications following permanent prostate brachytherapy," Eur. Urol. 41, 427-433 (2002).

${ }^{10}$ J. C. Blasko, T. Mate, J. E. Sylvester, P. D. Grimm, and W. Cavangah, "Brachytherapy for carcinoma of the prostate: Techniques, patient selection, and clinical outcomes," Semin. Radiat. Oncol. 12, 81-94 (2002)

${ }^{11}$ T. K. Podder, D. P. Clark, J. Sherman, D. Fuller, E. Messing, D. J. Rubens, J. G. Strang, Y. D. Zhang, W. O'Dell, W. S. Ng, and Y. Yu, "Effects of tip geometry of surgical needles: An assessment of force and deflection," 3rd European Medical and Biological Engineering Conference, Prague, Czech Republic, 2005, pp. 1641-1644.

${ }^{12}$ M. A. Meltsner, N. J. Ferrier, and B.R. Thomadsen, "Observations on rotating needle insertions using a brachytherapy robot," Phys. Med. Biol. 52, 6027-6037 (2007)

${ }^{13}$ N. Abolhassani, R. Patel, and F. Ayazi, "Effects of different insertion methods on reducing needle deflection," 29th Annual International Conference of the IEEE Engineering in Medicine and Biology Society, Lyon, France, 2007, pp. 491-494.
${ }^{14}$ T. K. Podder, W. S. Ng, and Y. Yu, "Multi-channel robotic system for prostate brachytherapy," 29th Annual International Conference of the IEEE Engineering in Medicine and Biology Society, Lyon, France, 2007, pp. $1233-1236$

${ }^{15}$ K. Yan, W. S. Ng, K. V. Ling, T. Liu, Y. Yu, and T. K. Podder, "High frequency translational oscillation \& rotational drilling of the needle in reducing target movement," IEEE International Symposium on Computational Intelligence in Robotics and Automation, Espoo, Finland, 2005, pp. 163-168.

${ }^{16}$ G. Wan, Z. Wei, L. Gardi, D.B. Downey, and A. Fenster, "Brachytherapy needle deflection evaluation and correction," Med. Phys. 32, 902-909 (2005).

${ }^{17}$ S. Jiang, N. Hata, and R. Kikinis, "Needle insertion simulation for imageguided brachytherapy of prostate cancer," 2nd International Conference on Bioinformatics and Biomedical Engineering, Shanghai, China, 2008 , pp. $1682-1685$.

${ }^{18}$ S. P. DiMaio and S. E. Salcudean, "Needle insertion modeling and simulation," IEEE Trans. Robot. Automat., 19, pp. 864-875 (2002).

${ }^{19}$ D. Glozman and M. Shoham, "Flexible needle steering and optimal trajectory planning for percutaneous therapies," Medical Image Computing and Computer-Assisted Intervention - MICCAI, Saint-Malo, France, 2004, pp. 137-144.

${ }^{20}$ N. Abolhassani, R. Patel, and M. Moallem, "Needle insertion into soft tissue: A survey," Med. Eng. Phys. 29, 413-431 (2007).

${ }^{21}$ C. S. McGill, J. A. Schwartz, J. Z. Moore, P. W. McLaughlin, and A. J. Shih, "Precision grid and hand motion for accurate needle insertion in brachythearpy," Med. Phys. 38, 4749-4759 (2011).

${ }^{22}$ M. Mahvash and P. E. Dupont, "Fast needle insertion to minimize tissue deformation and damage," IEEE International Conference on Robotics and Automation, Kobe, Japan, 2009, pp. 3097-3102.

${ }^{23}$ T. K. Podder, D. P. Clark, D. Fuller, J. Sherman, W. S. Ng, L. Liao, D. J. Rubens, J. G. Strang, E. M. Messing, Y. D. Zhang, and Y. Yu, "Effects of velocity modulation during surgical needle insertion," 27th Аnпиal International Conference of the IEEE Engineering in Medicine and Biology Society, Shanghai, China, 2005, pp. 5766-5770.

${ }^{24}$ V. Egorov, S. Tsyuryupa, S. Kanilo, M. Kogit, and A. Sarvazyan, "Soft tissue elastometer," Med. Eng. Phys. 30, 206-212 (2008).

${ }^{25} \mathrm{~L}$. Gao, Q. Zhang, and M. Liu, "Indentation test of soft tissue for investigating needle tissue machining," 2nd International Conference of Mechanic Automation and Control Engineering (MACE), Hohhot, China, 2011, pp. 348-351.

${ }^{26}$ American Society for Metals, ASM Handbook Vol. 6: Welding, Brazing, and Soldering (ASM International, Ohio, 1993).

${ }^{27}$ American Society for Metals, ASM Handbook Vol. 2: Properties and Selection: Nonferrous Alloys and Special-Purpose Materials (ASM International, Ohio, 1990).

${ }^{28}$ D. C. Montgomery, Design and Analysis of Experiments (Wiley, New York, 2005).

${ }^{29}$ V. Barnett and T. Lewis, Outliers in Statistical Data (John Wiley \& Sons, New York, 1994).

${ }^{30} \mathrm{~B}$. Iglewicz and D. C. Hoaglin, How to Detect and Handle Outliers (American Society for Quality Control, Wisconsin, 1993).

${ }^{31}$ K. V. Mardia, Statistics of Directional Data (Academic, New York, 1972). 